\title{
Improvement of the Assay Method for Steviol Glycosides in the JECFA Specifications
}

\author{
Atsuko Tada ${ }^{{ }^{*}}$, Kyoko Ishizuki ${ }^{1}$, Junichi Iwamura ${ }^{2}$, Hirohisa Mikami ${ }^{3}$, Yoshiko Hirao ${ }^{3}$, Isao Fujita ${ }^{4}$, \\ Takeshi Yamazaki ${ }^{1}$, Hiroshi Akiyama ${ }^{1}$, Yoko Kawamura ${ }^{1}$ \\ ${ }^{1}$ National Institute of Health Sciences, Tokyo, Japan \\ ${ }^{2}$ Laboratory of Creative Science Co., Ltd., Misonocho, Japan \\ ${ }^{3}$ Shimadzu Corporation, Kyoto, Japan \\ ${ }^{4}$ Morita Kagaku Kogyo Co., Ltd., Osaka, Japan \\ Email: ${ }^{*}$ atada@nihs.go.jp
}

Received February 25, 2013; revised March 20, 2013; accepted April 17, 2013

Copyright (C) 2013 Atsuko Tada et al. This is an open access article distributed under the Creative Commons Attribution License, which permits unrestricted use, distribution, and reproduction in any medium, provided the original work is properly cited.

\begin{abstract}
Steviol glycosides are natural sweetener constituents found in the leaves of Stevia rebaudiana Bertoni (Asteraceae). The specifications for steviol glycosides were established by the Joint FAO/WHO Expert Committee on Food Additives (JECFA) in 2008, although there was a call in the following year for the modification of this assay method to enable the determination of nine steviol glycosides rather than just seven. In response, based on a proposed method by the Japan Stevia Association, we developed an improved method by changing the HPLC conditions and including the use of an octadecylsilyl column instead of an amino-bonded column to enable the rapid and reliable determination of the nine steviol glycosides by an isocratic HPLC-UV method. With the developed method, the nine steviol glycosides can be separately determined, and identified using individual reference chemicals as standards, unlike the previous identification method, which was based on the relative retention times. In addition, the single stevioside quantification standard was replaced with both stevioside and rebaudioside A quantification standards. Importantly, the validation of the developed method was successful. The limits of quantification for the nine steviol glycosides were between $0.2 \%$ and $0.6 \%$. The developed assay method for the nine steviol glycosides was proposed to JECFA and adopted as the revised assay method for the steviol glycosides specifications at its 73rd meeting in 2010.
\end{abstract}

Keywords: Steviol Glycosides; Stevioside; Rebaudioside A; Reversed-Phase HPLC; JECFA Specifications

\section{Introduction}

Steviol glycosides are natural sweeteners found in the leaves of Stevia rebaudiana Bertoni (Asteraceae), and their principal components are stevioside and/or rebaudioside A. Stevia extract was accepted as an existing food additive by the Ministry of Health, Labor and Welfare in Japan (1996), and it has been used in many types of Japanese foods. The specifications for "steviol glycosides" were established by the FAO/WHO Joint Expert Committee on Food Additives (JECFA) in 2008 [1], and stevia extracts were also approved as generally recognized as safe by the US Food and Drug Administration that year. Since then, purified stevia extracts have been used throughout the world.

In the specifications established by JECFA in 2008 [1], the assay determined the concentrations of seven steviol

"Corresponding author. glycosides: stevioside, rebaudioside $\mathrm{A}$, rebaudioside $\mathrm{B}$, rebaudioside $\mathrm{C}$, dulcoside $\mathrm{A}$, rubusoside, and steviolbioside (Figure 1). These compounds were analyzed by HPLC using an amino-bonded column and identified by the zone method with relative retention times to that of rebaudioside $\mathrm{A}$.

In 2009, JECFA required that additional information for the detection of the steviol glycosides rebaudioside D and rebaudioside F (Figure 1) included in the assay method. In response to this request, the Japan Stevia Association (JSA) examined the existing test method and proposed a new one, which was then reviewed and improved by the National Institute of Health Sciences (NIHS), and the developed method was reproposed. With this new method, the nine steviol glycosides could be separately analyzed by HPLC using an octadecylsilyl (ODS) column. Moreover, each steviol glycoside was identified by an individual reference chemical rather than by the zone method, 


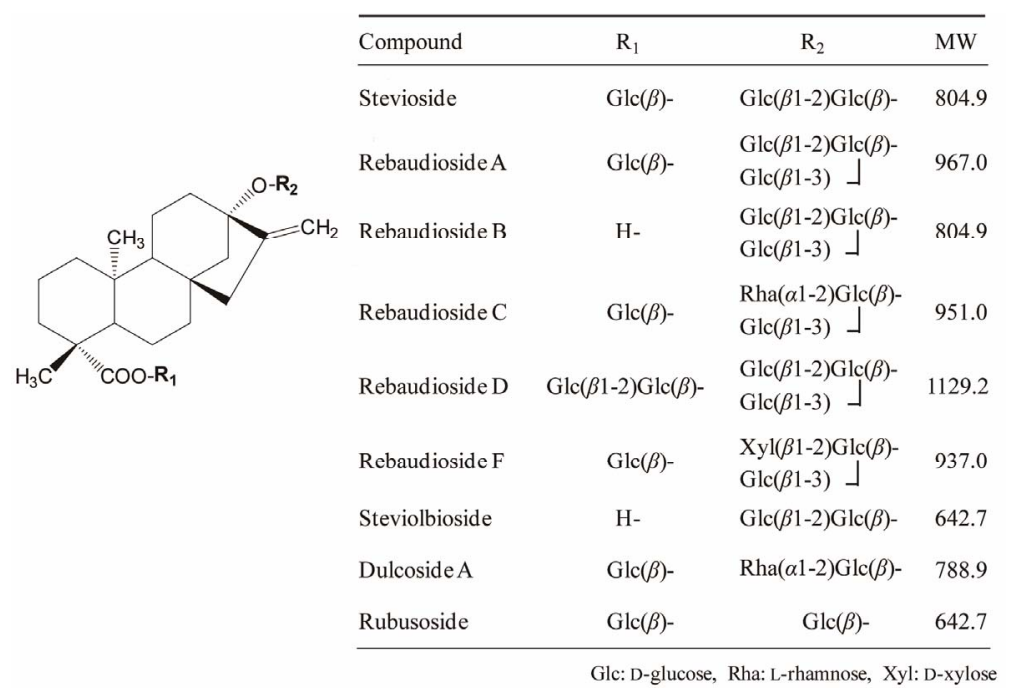

Figure 1. Structures and molecular weights of steviol glycosides.

and the quantification was achieved using both stevioside and rebaudioside A standards. Thus, this analysis provided higher accuracy and reliability. Subsequently, this method was adopted as the revised assay method for steviol glycosides at the 73rd JECFA meeting in 2010 [2]. This paper describes the basis of the new method developed by both JSA and NIHS.

\section{Experimental}

\subsection{Reagents and Samples}

The standards for stevioside (99.0+\% (HPLC, dried), Code No. 193-15351) and rebaudioside A (99.0+\% (HPLC, dried), Code No. 183-02361) used for the quantification were purchased from Wako Pure Chemical Industries Co., Ltd. (Osaka, Japan). The other seven steviol glycosides (rebaudioside $\mathrm{B}$, rebaudioside $\mathrm{C}$, rebaudioside $\mathrm{D}$, rebaudioside $\mathrm{F}$, dulcoside $\mathrm{A}$, rubusoside, and steviolbioside) were prepared from stevia extracts by the Laboratory of Creative Science Co., Ltd. (Osaka, Japan). The purity of rebaudioside F was approximately $20 \%$, while that of the other compounds was greater than $90 \%$. A reference standard mixture containing the nine steviol glycosides for peak identification was prepared by dissolving nine standards in a 30:70 (v/v) mixture of acetonitrile and water, which are currently marketed by Wako Pure Chemical Industries. Two samples of commercial stevia extracts used as food additives in Japan, RA95 and RA60, were obtained from Morita Kagaku Kogyo Co., Ltd., Japan.

\subsection{HPLC}

The analysis was performed using an Alliance 2695 HPLC system (Waters Co., MA, USA) with an SPD10AV UV-Vis detector (Shimadzu Corporation, Kyoto,
Japan). Separation was carried out on $4.6 \times 250 \mathrm{~mm}$ ODS columns with a particle size of $5 \mu \mathrm{m}$ : Capcell Pak C18 MGII (Shiseido Co., Ltd., Tokyo, Japan), Shim-pack CLC-ODS (Shimadzu Corporation), and Luna C18 (Phenomenex Co., Ltd., CA, USA). For comparison, a SunFire C18 column (Waters Co., Ltd.) and other ODS columns were also used. The column temperature was maintained at $40^{\circ} \mathrm{C}$. Elution was achieved using a 32:68 (v/v) mixture of acetonitrile and $10 \mathrm{mmol} / \mathrm{L}$ sodium phosphate buffer ( $\mathrm{pH} \mathrm{2.6)}$ as the mobile phase for $30 \mathrm{~min}$. The flow rate was maintained at $1.0 \mathrm{~mL} / \mathrm{min}$, and the chromatographic profile was monitored at $210 \mathrm{~nm}$.

For comparison, the existing JECFA method was performed using a Supelcosil LC-NH2 amino-bonded column (4.6 mm i.d. $\times 250 \mathrm{~mm}, 5 \mu \mathrm{m}$, Sigma-Aldrich Co., MO, USA). The column temperature was maintained at $40^{\circ} \mathrm{C}$. Elution was achieved at a flow rate of $1.0 \mathrm{~mL} / \mathrm{min}$ using an 80:20 (v/v) mixture of acetonitrile and water adjusted to a $\mathrm{pH}$ of 3.0 with phosphoric acid as the mobile phase, and the chromatographic profile was monitored at $210 \mathrm{~nm}$.

\subsection{Test Method}

For the standard solutions, each of the stevioside and rebaudioside A standards (50 $\mathrm{mg}$ each after drying at $105^{\circ} \mathrm{C}$ for $2 \mathrm{~h}$ ) was accurately weighed into separate 50 $\mathrm{mL}$ volumetric flasks, and the volume was made up with a 30:70 (v/v) mixture of acetonitrile and water. They were diluted as appropriate with the same solvent mixture. For the sample solutions, RA95 and RA60 (50 mg each after drying at $105^{\circ} \mathrm{C}$ for $2 \mathrm{~h}$ ) were accurately weighed into separate $50 \mathrm{~mL}$ volumetric flasks, and the volume was made up with a 30:70 (v/v) mixture of acetonitrile and water. The standard and sample solutions $(5 \mu \mathrm{L})$ were injected into the HPLC system. Steviol glycosides 
were identified on the basis of their correspondence of retention times using the reference standard mixture, and the peak areas were measured. Each solution was injected in triplicate, and the mean value was used for quantitation.

\subsection{Calculation of Steviol Glycoside Concentration}

The concentration of eight (not rebaudioside A) steviol glycosides $(x)$ in the sample was calculated by the following formula:

$$
C x(\%)=\frac{W_{s t v-s t n} \times f_{x} \times A_{x-s m p} \times 100}{W_{s m p} \times A_{s t v-s t n}}
$$

Here $C x(\%)$ is the concentration of a steviol glycoside, $W_{s t v-s t n}$ is the weight of the stevioside standard (dried basis), $W_{\text {smp }}$ is the weight of the sample (dried basis), $A_{x-s m p}$ is the peak area of the steviol glycoside $(x)$ in the sample solution, $A_{s t v-s t n}$ is the peak area of the stevioside in the standard solution, and $f x$ is the coefficient value for each steviol glycoside (1.00 (rebaudioside B), 1.18 (rebaudioside C), 1.40 (rebaudioside D), 1.16 (rebaudioside F), 0.98 (dulcoside A), 0.80 (rubusoside), or 0.80 (steviolbioside)).

The concentration of rebaudioside A in the sample was calculated by the following formula:

$$
C_{r e A(\%)}=\frac{W_{r e A-s t n} \times A_{r e A-s m p} \times 100}{W_{s m p} \times A_{r e A-s t n}}
$$

Here $C_{\text {reA }}(\%)$ is the concentration of rebaudioside $\mathrm{A}$, $W_{\text {reA-stn }}$ is the weight of the rebaudioside A standard (dried basis), $W_{s m p}$ is the weight of the sample (dried basis), $A_{\text {reA-smp }}$ is the peak area of rebaudioside $\mathrm{A}$ in the sample solution, and $A_{\text {reA-stn }}$ is the peak area of rebaudioside $\mathrm{A}$ in the standard solution.

The concentration of total steviol glycosides was then calculated from the sum of the nine steviol glycoside concentrations.

\section{Results and Discussion}

\subsection{Analysis Using the Existing JECFA Method}

In the JECFA method established in 2008 [1], each steviol glycoside was identified by the relative retention time to that of rebaudioside A. Figure 2 shows the HPLC chromatogram of the nine steviol glycosides obtained according to the method using the amino-bonded column.

As can be seen in Figure 2, newly added rebaudioside D appears at 40 min with a broad pattern and low sensitivity, although the other steviol glycosides are eluted within $20 \mathrm{~min}$. In addition, although we performed the analysis of the nine steviol glycosides using the identical amino-bonded column described in the original JECFA

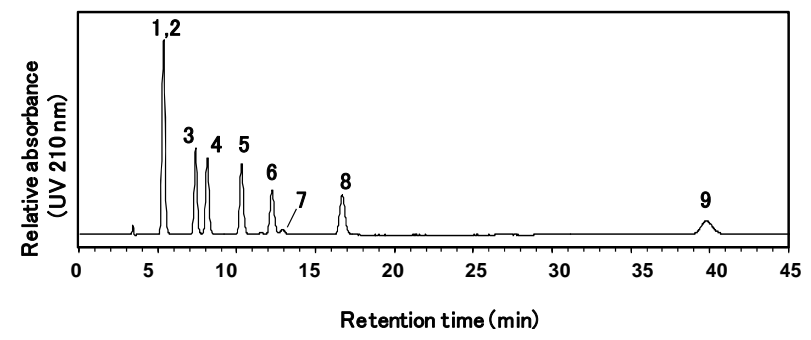

Figure 2. HPLC chromatogram of the reference standard mixture of nine steviol glycosides using an amino column as described in the conventional JECFA method. Separation was carried out on an supelcosil LC-NH2 column $(4.6 \mathrm{~mm}$ i.d. $\times 250 \mathrm{~mm}, 5 \mu \mathrm{m})$ at a column temperature of $40^{\circ} \mathrm{C}$ using an 80:20 (v/v) mixture of acetonitrile and water adjusted to a $\mathrm{pH}$ of 3.0 with phosphoric acid as the mobile phase at a flow rate of $1.0 \mathrm{~mL} / \mathrm{min}$. the eluted compounds were monitored at $210 \mathrm{~nm}$. 1: rubusoside, 2: steviolbioside, 3: dulcoside $A$, 4: rebaudioside $B, 5$ : stevioside, 6 : rebaudioside $C$, 7: rebaudioside $F$, 8: rebaudioside $A$, 9: rebaudioside $D$.

method, the peaks of rubusoside and steviolbioside were not fully separated, as shown in Figure 2. Moreover, some retention times of the peaks of the steviol glycolsides did not correspond with the relative retention times to that of rebaudioside $\mathrm{A}$ as described in the original JECFA method. We then attempted to separate the nine steviol glycosides using four other amino-bonded columns-Supelcosil LC-NH2-NP (4.6 mm i.d. $\times 250 \mathrm{~mm}, 5 \mu \mathrm{m}$, SigmaAldrich Co.), Asahipak NH2P-50 4E amino-bonded column (4.6 mm i.d. $\times 250 \mathrm{~mm}, 5 \mu \mathrm{m}$, Showa Denko Co., Ltd., Kawasaki, Japan), TSKgel NH2-100 (4.6 × 150 mm, $3 \mu \mathrm{m}$, Tosoh Co., Tokyo, Japan), and Wakosil 5NH2 (4.6 $\times 250 \mathrm{~mm}, 5 \mu \mathrm{m}$, Wako Pure Chemical Industries Co., Ltd.). Again, similar problems were observed (data not shown). Although the reason for the insufficient separation is unclear, the instability of ami no-bonded columns is one of the problems with the conventional method. The amino-bonded columns have a tendency to rapidly deteriorate. These results suggested that another type of column should be introduced. Therefore, we attempted to develop an analytical method to solve these problems.

\subsection{HPLC Using ODS Columns}

To solve these problems, the use of an ODS column was attempted for the determination of the nine steviol glycosides. With respect to the organic solvent for the mobile phase, acetonitrile was found to give a better separation than methanol (data not shown). Next, to determine the appropriate $\mathrm{pH}$ of the mobile phase, six mobile phases based on 32:68 (v/v) mixtures of acetonitrile and acidic solutions, including $10 \mathrm{mmol} / \mathrm{L}$ sodium phosphate buffer (pH 2.6), $1.4 \mathrm{mmol} / \mathrm{L}$ phosphoric acid ( $\mathrm{pH} 3.0), 5 \mathrm{mmol} / \mathrm{L}$ formic acid ( $\mathrm{pH} 3.0), 5 \mathrm{mmol} / \mathrm{L}$ ammonium formate $(\mathrm{pH}$ 6.1 ), and $5 \mathrm{mmol} / \mathrm{L}$ ammonium acetate $(\mathrm{pH} 6.6)$, and $\mathrm{H}_{2} \mathrm{O}$ were used. 
As shown in Figure 3, the nine steviol glycosides were separately detected within $30 \mathrm{~min}$ using five of the mobile phases under isocratic conditions. Only the mobile phase containing $5 \mathrm{mmol} / \mathrm{L}$ ammonium acetate $(\mathrm{pH}$ 6.6) was not effective (Figure 3(e)). Rebaudioside B and steviolbioside appear to elute faster using higher $\mathrm{pH}$ mobile phases. The mobile phase formulated with sodium phosphate buffer $(10 \mathrm{mmol} / \mathrm{L}, \mathrm{pH} 2.6)$ was found to provide the best peak shape and sensitivity (Figure 3(a)).

Next, the ratio of acetonitrile and $10 \mathrm{mmol} / \mathrm{L}$ sodium phosphate buffer ( $\mathrm{pH} 2.6)$ in the mobile phase was varied (35:65, 32:68, and 30:70). As can be seen in Figure 4(a), when the 35:65 (v/v) mixture of acetonitrile and sodium phosphate buffer was used as the mobile phase, the retention time of rebaudioside D was very close to the peak signal caused by injection shock. In the case of the 30:70 (v/v) mixture, rebaudioside B and steviolbioside were eluted after more than 30 min with broad peaks (Figure 4(c)). Both of the peaks of rebaudioside D and the injection shock were identically detected using other ODS

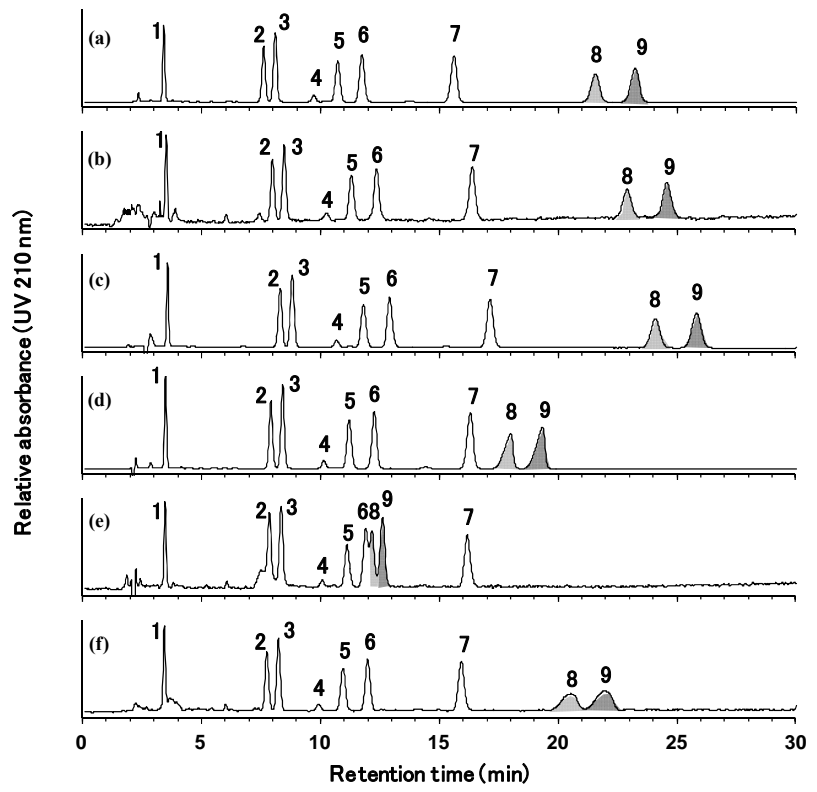

Figure 3. HPLC chromatograms of the reference standard mixtures of nine steviol glycosides obtained using an ODS column with six different mobile phases. the mobile phases were 32:68 (v/v) mixtures of acetonitrile and various solutions, including (a) $10 \mathrm{mmol} / \mathrm{L}$ sodium phosphate buffer (pH 2.6), (b) $1.4 \mathrm{mmol} / \mathrm{L}$ phosphoric acid (pH 3.0), (c) 5 $\mathrm{mmol} / \mathrm{L}$ formic acid (pH 3.0), (d) $5 \mathrm{mmol} / \mathrm{L}$ ammonium formate (pH 6.1), (e) $5 \mathrm{mmol} / \mathrm{L}$ ammonium acetate (pH 6.6), and (f) $\mathrm{H}_{2} \mathrm{O}$. Separation was carried out on a capcell pak C18 MGII column $(4.6 \mathrm{~mm}$ i.d. $\times 250 \mathrm{~mm}, 5 \mu \mathrm{m})$ at a column temperature of $40^{\circ} \mathrm{C}$ and a flow rate of $1.0 \mathrm{~mL} / \mathrm{min}$ and was monitored at $210 \mathrm{~nm}$. 1: rebaudioside $D, 2$ : rebaudioside $A$, 3: stevioside, 4: rebaudioside $F, 5$ : rebaudioside $C$, 6: dulcoside $A, 7$ : rubusoside, 8: rebaudioside $B$, 9: steviolbioside. columns (data not shown). Fortunately, with the 32:68 $(\mathrm{v} / \mathrm{v})$ mixture of acetonitrile and sodium phosphate buffer, the injection shock and rebaudioside D peaks were separated, and the rebaudioside $B$ and steviolbioside peaks had a good shape and retention time. Based on these results, the $32: 68(\mathrm{v} / \mathrm{v})$ mixture of acetonitrile and $10 \mathrm{mmol} / \mathrm{L}$ sodium phosphate buffer ( $\mathrm{pH}$ 2.6) was selected as the mobile phase. Under the analytical conditions, the UV spectra of the steviol glycosides showed the strongest UV absorption near 200 - $210 \mathrm{~nm}$ (data not shown).

To confirm the equality of different ODS columns, the analysis was carried out using more than six commercial ODS columns, and the results were compared. As can be seen in Figure 5, the elution patterns of the nine steviol glycosides were equivalent among four of the ODS columns, and the resolution of the rebaudioside A and stevioside peaks for the Capcell Pak C18 MGII (a), Shimpack CLC-ODS (b), Luna C18(2) (c), and SunFire C18 (d) columns was $1.65,1.60,1.55$, and 1.42 , respectively. However, stevioside and rebaudioside A could not be separated on some of the ODS columns (Figure 5(e)). Therefore, ODS columns with the appropriate level of resolution should be selected for the analysis of the nine steviol glycosides.

\subsection{Calibration Curves for the Developed Assay Method}

The calibration curves were constructed for a range of

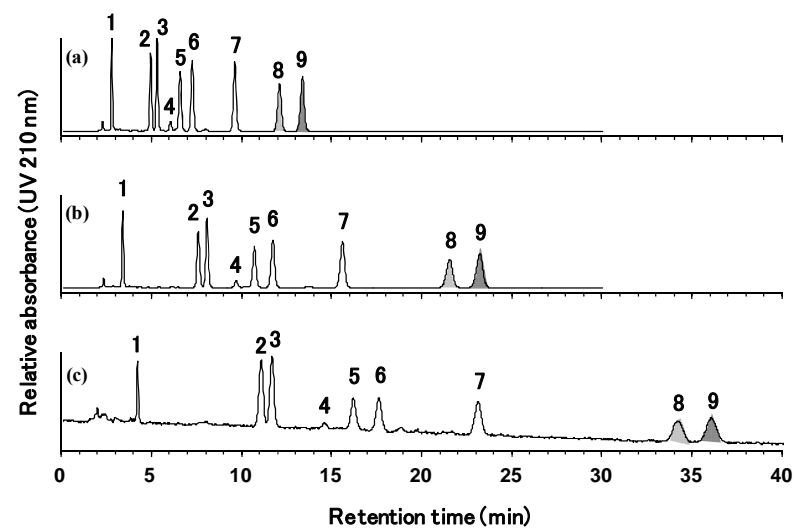

Figure 4. HPLC chromatograms of the reference standard mixture of nine steviol glycosides using different mobile phases. Mobile phases were 35:65 (v/v) mixtures of acetonitrile and $10 \mathrm{mmol} / \mathrm{L}$ sodium phosphate buffer (pH 2.6) (a), 32:68 (v/v) mixture of acetonitrile and $10 \mathrm{mmol} / \mathrm{L}$ sodium phosphate buffer (pH 2.6) (b) or 30:70 (v/v) mixture of acetonitrile and $10 \mathrm{mmol} / \mathrm{L}$ sodium phosphate buffer (pH 2.6) (c). Separation was carried out on capcell pak C18 MGII column $(4.6 \mathrm{~mm}$ i.d. $\times 250 \mathrm{~mm}, 5 \mu \mathrm{m})$ at a column temperature of $40^{\circ} \mathrm{C}$ and a flow rate of $1.0 \mathrm{~mL} / \mathrm{min}$. The eluted compounds were monitored at $210 \mathrm{~nm}$. 1: rebaudioside $D, 2$ : rebaudioside $A$, 3: stevioside, 4: rebaudioside $F$, 5: rebaudioside $C, 6$ : dulcoside $A, 7$ : rubusoside, 8: rebaudioside $B$, 9: steviolbioside. 
nine concentrations of the stevioside and rebaudioside $A$ standards (Figure 6). Good linearity was achieved over the concentration range from 0.001 to $2.0 \mathrm{mg} / \mathrm{mL}$ for both the stevioside and rebaudioside A standards. The correlation coefficients $\left(\mathrm{R}^{2}\right)$ for the two steviol glycolsides were more than 0.9999 . The limits of quantification (LOQ) $(\mathrm{S} / \mathrm{N}=10)$ for stevioside and rebaudioside $\mathrm{A}$ were $3 \mu \mathrm{g} / \mathrm{mL}$ each in the standard solutions and $0.3 \%$

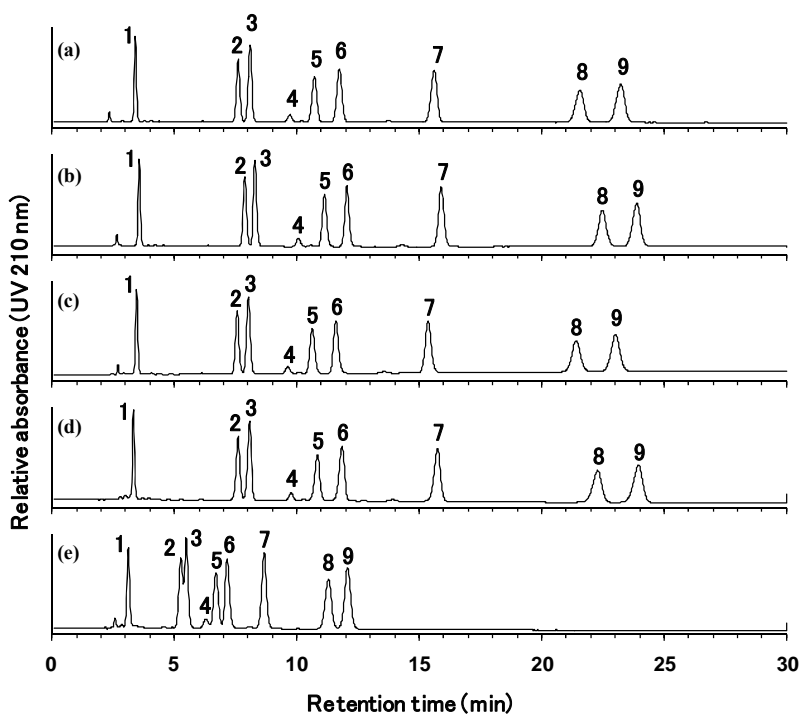

Figure 5. HPLC chromatograms of the reference standard mixture of nine steviol glycosides using different ODS columns $(4.6 \times 250 \mathrm{~mm}, 5 \mu \mathrm{m})$, Capcell Pak C18 MGII (a), Shim-pack CLC-ODS (b), Luna C18(2) (c), SunFire C18 (d), or other ODS column (e). Mobile phase was 32:68 (v/v) mixture of acetonitrile and $10 \mathrm{mmol} / \mathrm{L}$ sodium phosphate buffer. Separation was carried out at a column temperature of $40^{\circ} \mathrm{C}$ at the flow rate of $1.0 \mathrm{~mL} / \mathrm{min}$. The eluted compounds were monitored at $210 \mathrm{~nm}$. 1: rebaudioside $D, 2$ : rebaudioside $A$, 3: stevioside, 4: rebaudioside $F, 5$ : rebaudioside $C, 6$ : dulcoside $A, 7$ : rubusoside, 8: rebaudioside $B, 9$ : steviolbioside.

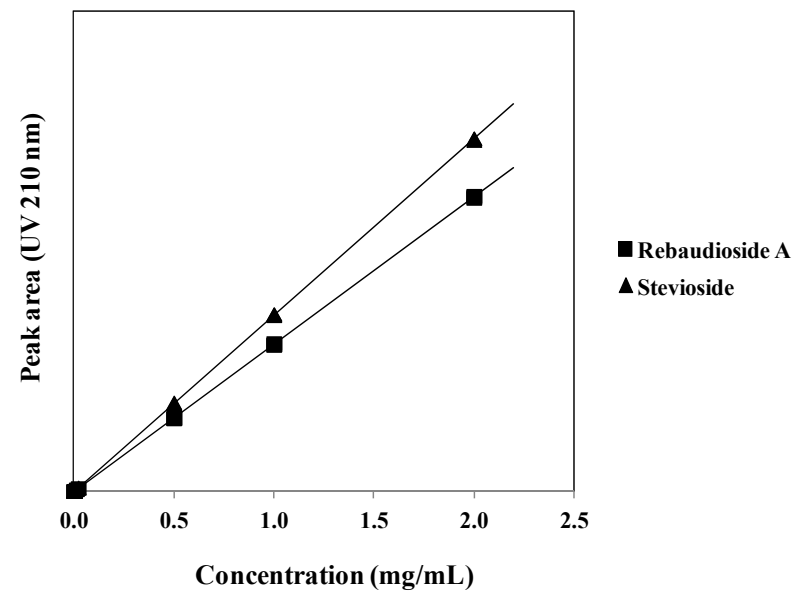

Figure 6. Calibration curves for the stevioside and rebaudioside A standards. each in the sample mixture. Good linearity was also achieved for the other seven steviol glycosides (data not shown) over the concentration range from approximately 0.001 to $0.5 \mathrm{mg} / \mathrm{mL}$ for rebaudioside $\mathrm{D}$, rebaudioside $\mathrm{C}$, dulcoside $\mathrm{A}$, rubusoside, rebaudioside $\mathrm{B}$, and steviolbioside, and $0.0001-0.1 \mathrm{mg} / \mathrm{mL}$ for rebaudioside $\mathrm{F}$. The correlation coefficients for the seven steviol glycosides were more than 0.999. LOQ $(\mathrm{S} / \mathrm{N}=10)$ for the seven steviol glycosides - rebaudioside $\mathrm{D}$, rebaudioside $\mathrm{F}$, rebaudioside $\mathrm{C}$, dulucoside $\mathrm{A}$, rubusoside, rebaudioside $\mathrm{B}$ and steviolbioside-were $2,4,4,4,4,6$, and $5 \mu \mathrm{g} / \mathrm{mL}$, respectively, in the standard solutions and $0.2 \%, 0.4 \%, 0.4 \%$, $0.4 \%, 0.4 \%, 0.6 \%$, and $0.5 \%$, respectively, in the sample mixture. Therefore, the linearity and sensitivity of the method are acceptable.

\subsection{Verification of the Developed Assay Method}

As shown in Table 1, the precision of the method was tested using multiple injections of high-purity samples of stevioside and rebaudioside $\mathrm{A}(\mathrm{n}=3)$. The relative standard deviation (RSD) for the amount of stevioside and rebaudioside A determined in the samples was calculated to be $0.41 \%$ and $0.70 \%$, respectively. These RSD values are acceptable.

\subsection{Application of the Developed Method to Commercial Stevia Extracts}

To ensure the applicability of the developed method, the quantities of the nine steviol glycosides in two types of commercial stevia extracts, RA 95 and RA 60, were determined. The reference standard mixture of the nine steviol glycosides was used for the identification of the peaks. As shown in Figure 7, both samples contained mainly rebaudioside A, although RA 60 also contained some levels of stevioside and rebaudioside $\mathrm{C}$.

The quantification results are summarized in Table 2. The values were calculated using the rebaudioside A standard for rebaudioside $\mathrm{A}$ and the stevioside standard for the other eight steviol glycosides. The percentage of total steviol glycosides in the two stevia extracts, RA95 and RA60, was $99.5 \%$ and $88.9 \%$, respectively.

Table 3 shows the quantified values of rebaudioside A and the total value of the steviol glycosides in the stevia extracts calculated using the rebaudioside A standard and the stevioside standard. Rebaudioside A was analyzed by the developed HPLC method, and then the levels of rebaudioside $\mathrm{A}$ in the stevia extracts, RA 95 and RA60, were determined by the two different calculation methods with the stevioside standard or the rebaudioside A standard. In the previous JECFA method, the rebaudioside A levels were determined using the stevioside standard as $f_{x}=1.20$ in Equation (1). However, in the developed method in this study, an actual rebaudioside A 


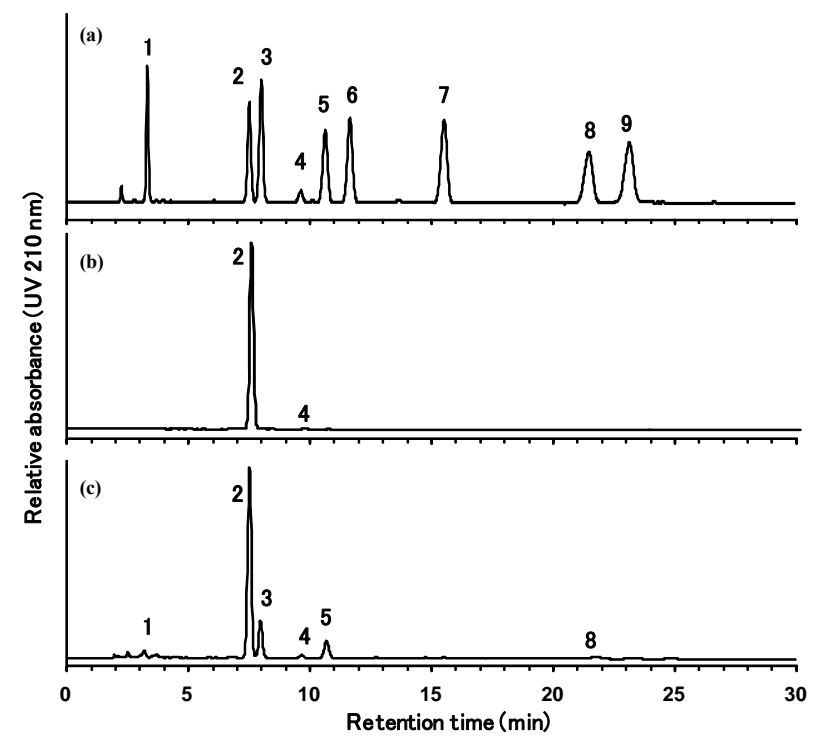

Figure 7. HPLC chromatograms of the reference standard mixture of nine steviol glycosides (a), stevia extracts used as food additives, RA 95 (b) and RA 60 (c). Separation was carried out on a Capcell Pak C18 MGII column $(4.6 \mathrm{~mm} \times$ $250 \mathrm{~mm}, 5 \mu \mathrm{m}$ ) at a column temperature at $40^{\circ} \mathrm{C}$ and a flow rate of $1.0 \mathrm{~mL} / \mathrm{min}$. The eluted compounds were monitored at $210 \mathrm{~nm}$. Mobile phase was 32:68 (v/v) mixture of acetonitrile and $10 \mathrm{mmol} / \mathrm{L}$ sodium phosphate buffer. 1: rebaudioside $D, 2$ : rebaudioside $A, 3$ : stevioside, 4: rebaudioside $F$, 5: rebaudioside $C$, 6: dulcoside $A, 7$ : rubusoside, 8: rebaudioside B, 9: steviolbioside.

Table 1. Quantification of stevioside and rebaudioside $A$ in their high-purity samples by the developed HPLC method.

\begin{tabular}{cccccc}
\hline \multirow{2}{*}{ Sample } & \multicolumn{5}{c}{ Content (\%) } \\
\cline { 2 - 6 } & $\mathrm{n}=1$ & $\mathrm{n}=2$ & $\mathrm{n}=3$ & Mean & RSD (\%) \\
\hline Stevioside & 99.8 & 100.5 & 100.4 & 100.4 & 0.41 \\
Rebaudioside A & 99.5 & 99.6 & 100.7 & 99.9 & 0.70 \\
\hline
\end{tabular}

standard was adopted for the determination of rebaudioside A, because high levels of rebaudioside A have recently been detected in many stevia extracts, and highpurity rebaudioside A standards have become commercially available. As shown in the table, the levels of rebaudioside A and total steviol glycosides in both RA95 and RA60 determined by the developed calculation method appear to be very slightly lower than those obtained by the previous calculation method. The levels obtained by the newly developed method are not significantly different from those obtained by the previous method, and both levels are within the range of the measurement error $(0.73 \%)$. Scientifically, in an HPLC quantification method, the target compound should be quantified by a standard curve based on a standard of the identical compound. The levels of rebaudioside A determined using the rebaudiosideA standard are more precise and reliable than
Table 2. Quantification of the nine steviol glycosides in stevia extracts used as food additives using HPLC.

\begin{tabular}{ccccc}
\hline & \multicolumn{4}{c}{$\begin{array}{c}\text { Content } \\
(\%)^{\mathrm{a}}\end{array}$} \\
\cline { 2 - 5 } Steviol glycoside & RA95 & \multicolumn{3}{c}{ RA60 } \\
\cline { 2 - 5 } & Mean & \pm SD & Mean & \pm SD \\
\hline Rebaudioside D & 0.24 & 0.01 & 2.09 & 0.08 \\
Rebaudioside A & 98.7 & 0.73 & 65.3 & 0.73 \\
Stevioside & ND & & 10.7 & 0.08 \\
Rebaudioside F & 0.52 & 0.00 & 1.35 & 0.01 \\
Rebaudioside C & ND & & 7.56 & 0.09 \\
Dulcoside A & ND & & ND & \\
Rebaudioside B & ND & & 1.41 & 0.03 \\
Rubusoide & ND & & 0.45 & 0.01 \\
Steviolbioside & ND & & ND & \\
Total & 99.5 & 0.73 & 88.9 & 0.99 \\
steviol glycoside & & & & \\
\hline
\end{tabular}

${ }^{a}$ On the dried basis. ${ }^{b}$ Rebaudioside A was quantified by rebaudioside A standard. ${ }^{\mathrm{C}} \mathrm{ND}$ : Not detected. Each value is a mean of three trials.

Table 3. Comparison of the rebaudioside A concentration in stevia extracts using the two different calculation methods.

\begin{tabular}{ccccc}
\hline & \multicolumn{4}{c}{ Content (\%) } \\
\cline { 2 - 5 } & \multicolumn{2}{c}{$\begin{array}{c}\text { Previous calculation } \\
\text { method }^{\mathrm{b}}\end{array}$} & \multicolumn{2}{c}{$\begin{array}{c}\text { Developed } \\
\text { calculation } \text { method }^{\mathrm{c}}\end{array}$} \\
\cline { 2 - 5 } & RA95 & RA60 & RA95 & RA60 \\
\hline $\begin{array}{c}\text { Rebaudioside A } \\
\text { Total steviol } \\
\text { glycoside }\end{array}$ & 99.1 & 65.6 & 98.7 & 65.3 \\
\hline
\end{tabular}

${ }^{\mathrm{a}}$ On the dried basis. ${ }^{\mathrm{b}}$ Rebaudioside A was quantified by stevioside standard. ${ }^{\mathrm{c}}$ Rebaudioside A was quantified by rebaudioside A standard.

those obtained using a standard that is a different compound and requires coefficient value, particularly for stevia extracts with high concentrations of rebaudioside A. Therefore the rebaudioside A standard was used for the quantification of rebaudioside $\mathrm{A}$ in the developed method.

\section{Conclusion}

We developed an isocratic HPLC-UV method by employing an ODS column using a reference standard mixture of nine steviol glycosides. On the ODS column, the steviol glycosides can be detected separately and sensitively within $30 \mathrm{~min}$. In addition, the use of the reference standard mixture of nine steviol glycosides enables the correct identification of the steviol glycosides in different samples. The reference standard mixture of the nine ste- 
viol glycosides is now commercially available. The rapid and reliable determination of the nine steviol glycosides by an isocratic HPLC-UV method on an ODS column was first developed in this study and has not been previously reported [3-7]. Subsequently, this method was proposed as the revised assay method for steviol glycosides and adopted at the 73rd JECFA meeting in 2010 [2] .

\section{Acknowledgements}

We are grateful to Wako Pure Chemical Industries Ltd., Maruzen Pharmaceuticals Ltd., Morita Kagaku Kogyo Ltd., the Japan Stevia Industry Association, and the Japan Food Additives Association for providing noncommercial steviol glycosides, stevia extract samples, and information on stevia extracts. This work was supported by a Grant-in-Aid for Scientific Research from the Ministry of Health, Welfare, and Labor of Japan.

\section{REFERENCES}

[1] Joint FAO/WHO Expert Committee on Food Additives (JECFA), "Steviol Glycosides," Compendium of Food Additive Specifications, Monograph 5, 2008.

[2] Joint FAO/WHO Expert Committee on Food Additives (JECFA), "Steviol Glycosides," Compendium of Food Additive Specifications, Monograph 10, 2010.
[3] C. Gardana, M. Scaglianti and P. Simonetti, "Evaluation of Steviol and Its Glycosides in Stevia Rebaudiana Leaves and Commercial Sweetener by Ultra-High-Performance Liquid Chromatography-Mass Spectrometry," Journal of Chromatography A, Vol. 1217, No. 9, 2010, pp. 14631470 .

[4] U. Woelwer-Rieck, C. Lankes, A. Wawrzun and M. Wuest, "Improved HPLC Method for the Evaluation of the Major Steviol Glycosides in Leaves of Stevia Rebaudiana," European Food Research and Technology, Vol. 231, No. 4, 2010, pp. 581-588. doi:10.1007/s00217-010-1309-4

[5] F. Ni, J. Ammann and A. Mabud, "Monitoring Stevioside in Soju by High-Performance Liquid Chromatography and Liquid Chromatography/Mass Spectrometry," Journal of AOAC International, Vol. 90, No. 5, 2007, pp. 13651372.

[6] N. Kolb, J. L. Herrera, D. J. Ferreyra and R. F. Uliana, "Analysis of Sweet Diterpene Glycosides from Stevia Rebaudiana: Improved HPLC Method," Journal of Agricultural and Food Chemistry, Vol. 49, No. 10, 2001, pp. 45384541. doi:10.1021/jf010475p

[7] H. C. Makapugay, N. P. D. Nanayakkara and A. D. Kinghorn, "Improved High-Performance Liquid Chromatographic Separation of the Stevia Rebaudiana Sweet Diterpene Glycosides Using Linear Gradient Elution," Journal of Chromatography, Vol. 283, 1984, pp. 390-395. doi:10.1016/S0021-9673(00)96278-2 